\title{
Development and validation of the Health Promoting Behaviour for Bloating (HPB-Bloat) scale
}

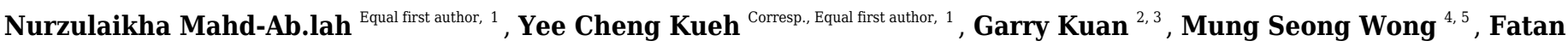 \\ Hamamah Yahaya ${ }^{6}$, Nor Aslina Abd Samat ${ }^{5,7}$, Khairil Khuzaini Zulkifli ${ }^{7,8}$, Yeong Yeh Lee ${ }^{5,7,9}$ \\ 1 Biostatistics \& Research Methodology Unit, School of Medical Sciences, Universiti Sains Malaysia, Kubang Kerian, Kelantan, Malaysia \\ 2 Exercise and Sport Science, School of Health Sciences, Universiti Sains Malaysia, Kubang Kerian, Kelantan, Kelantan, Malaysia \\ 3 Department of Life Sciences, Brunel University, London, United Kingdom \\ 4 Department of Medicine, Universiti Sains Malaysia, Kubang Kerian, Kelantan, Kelantan, Malaysia \\ 5 Hospital Universiti Sains Malaysia, Universiti Sains Malaysia, Kubang Kerian, Kelantan, Malaysia \\ ${ }^{6}$ School of Distance Education, Universiti Sains Malaysia, Penang, Malaysia \\ 7 Department of Medicine, Universiti Sains Malaysia, Kubang Kerian, Kelantan, Malaysia \\ 8 Faculty of Medicine, Universiti Teknologi MARA, Sungai Buloh, Selangor, Malaysia \\ 9 Gut Research Group, Faculty of Medicine, National University of Malaysia, Kuala Lumpur, Malaysia \\ Corresponding Author: Yee Cheng Kueh \\ Email address: yckueh@usm.my
}

Background. Health management strategies may help patients with abdominal bloating ( $A B)$, but there are currently no tools that measure behaviour and awareness. This study aimed to validate and verify the dimensionality of the newly-developed Health Promoting Behaviour for Bloating (HPB-Bloat) scale.

Methods. Based on previous literature, expert input, and in-depth interviews, we generated new items for the HPB-Bloat. Its content validity was assessed by experts and pre-tested across 30 individuals with AB. Construct validity and dimensionality were first determined using exploratory factor analysis (EFA) and Promax rotation analysis, and then using confirmatory factor analysis (CFA).

Results. During the development stage, 35 items were generated for the HPB-Bloat, and were maintained following content validity assessment and pre-testing. One hundred and fifty-two participants (mean age of 31.27 years, $68.3 \%$ female) and 323 participants (mean age of 27.7 years, $59.4 \%$ male) completed the scale for EFA and CFA, respectively. Using EFA, we identified 20 items that we divided into five factors: diet (five items), health awareness (four items), physical activity (three items), stress management (four items), and treatment (four items). The total variance explained by the EFA model was $56.7 \%$. The Cronbach alpha values of the five factors ranged between 0.52 and 0.81 . In the CFA model, one problematic latent variable (treatment) was identified and three items were removed. In the final measurement model, four factors and 17 items fit the data well based on several fit indices (root mean square error of approximation (RMSEA) $=0.044$ and standardized root mean squared residual $(S R M R)=$ 0.052 ). The composite reliability of all factors in the final measurement model was above 0.60 , indicating acceptable construct reliability.

Conclusion. The newly developed HPB-Bloat scale is valid and reliable when assessing the awareness of health-promoting behaviours across patients with AB. Further validation is needed across different languages and populations.

$<!--[e n d i f]-->$

Peer) reviewing PDF | (2020:08:51849:2:0:NEW 17 Feb 2021) 
1 Development and validation of the Health Promoting

2 Behaviour for Bloating (HPB-Bloat) scale

3 Nurzulaikha Mahd-Ab.lah', Yee Cheng Kueh ${ }^{1 *}$, Garry Kuan², Mung Seong Wong,,

4 Fatan Hamamah Yahaya ${ }^{6}$, Nor Aslina Abd Samat ${ }^{4,5}$, Khairil Khuzaini Zulkifli, ${ }^{4,7}$, Yeong

5 Yeh Lee L,5,8 $^{4}$

61 Biostatistics and Research Methodology Unit, School of Medical Sciences, Universiti

$7 \quad$ Sains Malaysia, Kubang Kerian, Kelantan, Malaysia

82 Exercise and Sport Science, School of Health Sciences, Universiti Sains Malaysia,

$9 \quad$ Kubang Kerian, Kelantan, Malaysia

103 Department of Life Sciences, Brunel University, London, United Kingdom

114 Department of Medicine, School of Medical Sciences, Universiti Sains Malaysia, Kubang

5 Hospital Universiti Sains Malaysia, Universiti Sains Malaysia, Kubang Kerian, Kelantan, Malaysia

6 School of Distance Education, Universiti Sains Malaysia, Pulau Pinang, Malaysia

Corresponding author:

Yee Cheng Kueh ${ }^{*}$

Biostatistics and Research Methodology Unit, School of Medical Sciences, Universiti Sains Malaysia, Kubang Kerian, Kelantan, Malaysia

Email address: yckueh@usm.my Gut Research Group, Faculty of Medicine, National University of Malaysia, Kuala Lumpur, Malaysia

Email address: yckueh@usm.my 


\section{Abstract}

Background. Health management strategies may help patients with abdominal bloating (AB), but there are currently no tools that measure behaviour and awareness. This study aimed to validate and verify the dimensionality of the newly-developed Health Promoting Behaviour for Bloating (HPB-Bloat) scale.

Methods. Based on previous literature, expert input, and in-depth interviews, we generated new items for the HPB-Bloat. Its content validity was assessed by experts and pre-tested across 30 individuals with $\mathrm{AB}$. Construct validity and dimensionality were first determined using exploratory factor analysis (EFA) and Promax rotation analysis, and then using confirmatory factor analysis (CFA).

Results. During the development stage, 35 items were generated for the HPB-Bloat, and were maintained following content validity assessment and pre-testing. One hundred and fifty-two participants (mean age of 31.27 years, $68.3 \%$ female) and 323 participants (mean age of 27.7 years, 59.4\% male) completed the scale for EFA and CFA, respectively. Using EFA, we identified 20 items that divided into five factors: diet (five items), health awareness (four items), physical activity (three items), stress management (four items), and treatment (four items). The total variance explained by the EFA model was $56.7 \%$. The Cronbach alpha values of the five factors ranged between 0.52 and 0.81 . In the CFA model, one problematic latent variable (treatment) was identified and three items were removed. In the final measurement model, four factors and 17 items fit the data well based on several fit indices (root mean square error of approximation $($ RMSEA) $=0.044$ and standardized root mean squared residual $(\mathrm{SRMR})=$ 0.052). The composite reliability of all factors in the final measurement model was above 0.60 , indicating acceptable construct reliability.

Conclusion. The newly developed HPB-Bloat scale is valid and reliable when assessing the awareness of health-promoting behaviours across patients with AB. Further validation is needed across different languages and populations.

\section{Introduction}

Abdominal bloating $(\mathrm{AB})$ is a common symptom that can be associated with impaired quality of life and psychological dysfunction. The most recent global epidemiology survey of functional gastrointestinal (GI) disorders involved 73,000 respondents and found that the prevalence of functional $\mathrm{AB}$ and distension was $3.5 \%$ and $1.2 \%$, respectively (Sperber et al., 2020). There are a number of lifestyle risk factors that may trigger or aggravate $A B$, including physical inactivity, stress, and obesity (Cai Lian et al., 2016; Cook \& Schoeller, 2011; Graff et al., 2006). However, studies on the effects of bowel disorders, such as AB, on lifestyle routines have yielded disparate findings (Fernández-Bañares et al., 2006; Lacy et al., 2009).

The majority of differences in self-reported lifestyles are related to sedentary behaviours and eating habits. Prince et al. (2008) found that physical inactivity and sedentary behaviours were associated with fluctuating mortality and morbidity rates (WHO, 2018). Researchers have also found that stress, anxiety, sleep problems, and somatic symptoms were independent predictors of GI disorders (Nicholl et al., 2008), including bloating (O'Malley et al., 2011). According to the National Health and Morbidity Survey (NHMS), mental health problems were observed in 29.2\% of Malaysians aged 16 and older (Mustapha, 2018). Other less common, but 
82

83

84

85

86

87

88

89

90

91

92

93

94

95

96

97

98

99

100

101

102

103

104

105

106

107

108

109

110

111

112

113

114

115

116

117

118

119

120

121

122

123

124

125

126

127

equally as important, risk factors for $\mathrm{AB}$ are eating and dietary habits. A university student in Taiwan reportedly died from stomach cancer after consuming instant noodles on a daily basis and having chronic bloating, nausea, and stomachache symptoms (NST, 2018). Eating an imbalanced diet can lead to obesity, which can cause many different health problems (Rashid, 2017; WHO, 2019). Obesity is recognized as an important contributing factor to GI symptoms including AB (Delgado-Aros et al., 2004; Ho \& Spiegel, 2008).

A study by Kua et al. (2012) reported that $4.2 \%$ of patients in Singapore that sought selfmedications were from the cohort that experienced bloating symptoms. However, positive improvements can be seen using non-drug approaches for bloating (Khoshoo et al., 2006; Lacy et al., 2009), including changing dietary habits (Fernández-Bañares et al., 2006), using pro- and/or prebiotics (Kim et al., 2005; McFarland \& Dublin, 2008; Moayyedi et al., 2010; Vulevic et al., 2018), cognitive-behaviour therapy (Boyce et al., 2000; Drossman et al., 2003), herbs (Liu et al., 2006; Vejdani et al., 2006), and ointment or massage (Lämås et al., 2009; Lotfipur-Rafsanjani et al., 2018). Treatments for known disorders that cause bloating, such as constipation (Han et al., 2018; Lämås et al., 2009), can also help bloating (Foley et al., 2014; Johannesson, 2015).

However, each treatment used on its own has different reported success rates due to heterogeneity in use, dose, and compliance.

Due to the limitations described above, creating an environment and adopting good practices and behaviour in order to facilitate a healthy lifestyle may be a more suitable strategy in AB management. This is the basis for the theory of planned behaviour (TPB) (Viner \& Macfarlane, 2005). The framework of the TPB consists of belief, intention, and behaviour, with behaviour as the central core (Ajzen, 1991). Self-management behaviours were observed to influence the quality of life in patients with type 2 diabetes mellitus (Kueh et al., 2015; 2017). The TPB proposes that beliefs (based on attitudes, subjective norms, and perceived behavioural control) influence intention, which further affects behaviour. Past behaviour can also act an additional predictor of a person's current intention and behaviour (McEachan \& Conner, 2011; Thomson et al., 2012; Abdullah et al., 2020). In addition to looking at the effects of past behaviours on current intentions and behaviours, the efficacy of the TPB in predicting healthrelated behaviours is also influenced by behaviour type, sample characteristics, and methodological factors (McEachan \& Conner, 2011). Therefore, exploring suitable healthpromoting behaviours is important in order to increase awareness across people who suffer with $\mathrm{AB}$. A validated tool that can evaluate the health-promoting behaviours of $\mathrm{AB}$ patients is needed, and our study aimed to develop and validate a scale that could assess these behaviours.

\section{Materials and methods}

\section{Study design, sampling method, and participants}

Using a cross-sectional study design with purposive sampling, we conducted our study between May 2018 and October 2019. A total of 520 people from the compound of the Hospital Universiti Sains Malaysia (HUSM), Kelantan, Malaysia were screened. Ultimately, 510 (98.1\%) participants were deemed eligible and were recruited for the study. The participants consisted of patients, caregivers, accompanying persons, hospital staff, and students around HUSM. The inclusion criteria were: age 18 years and older, a functional bloating diagnosis (based on the Rome IV criteria or a clinical diagnosis), and/or experience of bloating at least once in the past 3 months (based on an answer to the verbal question "Have you ever experienced bloating?" 
128

129

130

131

132

133

134

135

136

137

138

139

140

141

142

143

144

145

146

147

148

149

150

151

152

153

154

155

156

157

158

159

160

161

162

163

164

165

166

167

168

169

170

171

172

173

and/or using a pictogram from the Rome foundation). A clinical diagnosis of bloating was made based on the experience of the physicians who managed functional GI disorders. The exclusion criteria were: an absence of a history of organic GI diseases (e.g., inflammatory bowel disease, GI infections, and colorectal cancer), a history of abdominal surgeries, taking drugs that may cause or worsen bloating (e.g., opiates), and any severe psychiatric illnesses (e.g., schizophrenia). Appropriate eligibility criteria is important and can impact external validity when designing a study (Patino \& Ferreira, 2018). These specific criteria were chosen in order to cover the adult general population that were not affected by severe diseases.

\section{Ethical approval}

Ethical approval was obtained from the Human Research Ethics committee, Universiti Sains Malaysia [USMKK/PPP/JEPEM/17010012] prior to the start of the study. This study also conformed to the guidelines set by the International Declaration of Helsinki. Written informed consent was obtained from each participant.

\section{Developing the HPB-Bloat}

The new HPB-Bloat scale was developed to measure health-promoting behaviours across people with $\mathrm{AB}$, and was based on the TPB, one of the most commonly-used and well-validated decision-making models that examines attitude and behaviour. We employed the theory, driven with the approach of dimension/indicator analysis that was described by Hox (1997). Based on our research of the literature and discussions with the research team experts, we conceptualized $\mathrm{AB}$ health behaviours across five domains: diet, health awareness, physical activity, stress management, and treatment. The new item generation was conducted by the researchers through an extensive literature review related to health behaviours that could encourage improvements in AB symptoms. Based on the literature review, a total of 24 items were generated. The research team experts also provided an additional 10 related items and supported the five temporary domains from the early draft of the HPB-Bloat scale. In order to cover all of the important indicators for the behaviour construct, we conducted an in-depth interview of 12 individuals with AB symptoms. The in-depth interview was conducted using guided questions. For example, "What do you think about AB in daily life?", and "How do you manage AB in daily life?" Additional probing questions that focused on specific activities used to manage symptoms included "How about your dietary intake? Does it contribute to improve your AB symptoms?", "How about physical activity? Does it contribute to improve your AB symptoms?", "How about stress management? Does it contribute to improve your AB symptoms?", and "Are there any other things that help you deal with AB? If so, is it helpful and how does it help?". The duration of the interview was approximately 30 minutes to 1 hour. All the recorded interviews were transcribed into a transcript, which was then narratively analysed. Themes were identified from the transcript, a theme list was created, and interview segments were coded. Important aspects and critical points from the interviewed individuals were identified. From these interviews, we found an additional item that we added to the HPB-Bloat's item pool. Hence, a total of 35 items were generated in the initial stage of developing the first draft of the HPB-Bloat. The responses for each item were rated using a five-point Likert-scale, from never (1) to very often (5). All items were developed in the Malay language, which is the main spoken language in the study's location. The first draft of the HPB-Bloat was then examined for its content validity by seven invited experts, who each had at least 10 years of experience in the GI field, psychometric testing, language, and questionnaire development. Figure 1 shows the item generation process 
174 from the initial stage of development to the final stage of item reduction for the newly developed 175 HPB-Bloat.

176

177

178

179

180

181

182

183

184

185

186

187

188

189

190

191

192

193

194

195

196

197

198

199

200

201

202

203

204

205

206

207

208

209

210

211

212

213

214

215

216

217

218

[Figure 1]

\section{Content validity and pre-testing of the HPB-Bloat}

To assess content validity, we computed content validity indices for the items (I-CVI) and scale (S-CVI) based on the relevant responses from the invited experts (Lynn, 1986; Polit \& Beck, 2006). Using the average method (S-CVI/Ave), we found that the items' content validity index and the scale's content validity index for the five expected domains (or factors) in the HPB-Bloat were all more than 0.75, which we considered satisfactory (Lynn, 1986).

Subsequently, we conducted pre-testing on 30 participants diagnosed with functional bloating (based on Rome IV or a clinical diagnosis). The invited participants were asked to comment on the clarity and comprehensibility of the administered HPB-Bloat. The format and font sizes were modified based on suggestions from the participants. However, the structure and wording of items remained unchanged.

Based on the results from the CVIs (using I-CVI and S-CVI/Ave) and pre-testing, the first version of the HPB-Bloat remained at 35 items. In order to determine the validity and reliability of this HPB-Bloat draft, we performed an exploratory factor analysis (EFA), followed by a confirmatory factor analysis (CFA).

\section{Data and statistical analysis}

The EFA and CFA were performed using the Statistical Package for Social Sciences (SPSS) version 24.0 (IBM, Armonk, NY, USA) and Mplus 8 (Muthen \& Muthen, 1998-2017). The variables were expressed as mean and standard deviation (SD) for numerical items and frequency (n) and percentage (\%) for categorical variables.

The EFA was first performed on the initial 35 items in order to explore and extract the major contributing factors, using the principal axis factoring with Promax rotation (Kappa 4). We decided the number of factors based on the eigenvalue, which should be greater than one. Factor loadings greater than 0.40 were regarded as significantly relevant and items with greater loadings were considered problematic and were deleted (Hair et al., 2010). All item deletions were conducted in a consecutive manner and subsequent models were re-specified following each deletion. The reliability of the factors was checked using internal consistency based on Cronbach's alpha, with the generally recommended threshold value of 0.60 (Taber, 2018). However, a value above 0.50 is still considered acceptable by some literature (George \& Paul Mallery, 2003; Hinton et al., 2004; Karin et al., 2019).

Following EFA, we tested the final structure model with CFA to further confirm its validity. Items with factor loadings less than 0.40 were removed after adequate theoretical support was carried out by researchers. The modification indices (MI) were used as a guide to improve the model by adding the items' residual correlation. Modifications to the model were based on theoretical basis and expert opinion.

The measurement CFA model was assessed using several fit indices (Kline, 2011). The fit indices and the recommended threshold values were: a standardized root mean squared residual (SRMR) value lower than 0.70, a root mean square error of approximation (RMSEA) value lower than 0.80, and a comparative fit index (CFI) and Tucker-Lewis Fit Index (TFI) 
219

220

221

222

223

224

225

226

227

228

229

230

231

232

233

234

235

236

237

238

239

240

241

242

243

244

245

246

247

248

249

250

251

252

253

254

255

256

257

258

259

260

261

262

263

264

values above 0.92 for items 12 to 30 (Hair et al., 2010). The CFA model was re-specified with adequate theoretical support until most of the model fit indices met the criteria.

We used the correlation matrices among the latent constructs to establish discriminant validity. The composite reliability of the measurement CFA model was computed (Hair et al., 2010). Composite reliability greater than the threshold value of 0.60 was considered acceptable (Hair et al., 2010).

\section{Results}

A total of 160 and 350 HPB-Bloat scales were distributed to AB patients for EFA and CFA, respectively. One hundred and fifty-two (95.0\%) and $323(92.3 \%)$ participants completed the HPB-Bloat scales for EFA and CFA, respectively. The mean age of respondents for EFA was 31.7 years old $(\mathrm{SD}=14.36)$ and $68.3 \%$ were female. For $\mathrm{CFA}$, the mean age of respondents was 27.7 years old $(\mathrm{SD}=11.50)$ and $59.4 \%$ were male.

\section{The EFA model}

Our results indicated adequate sampling and reliable estimates (Kaiser-Meyer-Olkin Measure of Sampling Adequacy $(\mathrm{KMO})=0.732$, Bartlett's test of sphericity $=p<0.001$; Yong \& Pearce, 2013). The 35 initial items, divided into five factors, were represented with a cumulative value of $56.7 \%$ of the variance, which indicated acceptable importance. The variance value for each of the five factors was $22.25,10.91,9.58,7.26$, and 6.65 , respectively.

We removed the problematic items from the subsequent EFA models until we achieved a final model with all factor loadings greater than 0.40 . Three items with factor loadings less than $0.40(\mathrm{~T} 5=0.349, \mathrm{SM} 1=0.287$, and D2=0.370) were kept for further analysis. Eventually, we removed 15 items and the final model consisted of 20 items. The descriptive statistics, factor loading, and internal consistency results of the final EFA model are summarized in Table 1. The five factors described were diet, health awareness, physical activity, stress management, and treatment. The internal consistency corresponded with the reported Cronbach's alphas, ranging from a low of 0.52 (stress management) to a high of 0.81 (health awareness).

[Table 1]

\section{The CFA model}

As shown in Table 2, the results of the initial 20-item CFA model revealed that none of the model fit indices met the criteria. Additionally, the CFA output showed that the latent variable covariance matrix was not positive definite, and there was a problem involving the treatment factor. Therefore, we subjected the initial model to re-specification for improvement. The CFA output indicated that the treatment factor had a high standardized correlation $(>1)$ with the diet factor. However, we found that both factors had items that made them not suitable to be combined into one factor. We further investigated the meaning of the four items under the treatment factor. We removed these items iteratively from the initial CFA model, except for item T4 ("I will always be ready to try new treatment techniques to improve AB symptoms when needed"), which has a treatment awareness component. Therefore, we grouped item T4 under the health awareness factor and renamed the factor as health and treatment awareness. After removing the treatment factor, Model-1 consisted of four factors with 17 items (Table 3). The fit indices were improved in Model-2, but CFI and TLI were still not within the acceptable threshold values. Based on the MI results and following adequate theoretical support carried out 
265

266

267

268

269

270

271

272

273

274

275

276

277

278

279

280

281

282

283

284

285

286

287

288

289

290

291

292

293

294

295

296

297

298

299

300

301

302

303

304

305

306

307

308

309

310

by the researchers, we added residual correlations from several items within the same factor into the model, one by one. The final model (Model 2) fit the data well based on several fit indices: $\mathrm{CFI}=0.929, \mathrm{TLI}=0.911, \mathrm{SRMR}=0.052$, and RMSEA $=0.044(0.032,0.061)$ (Table 2, Model2).

[Table 2]

As Table 3 illustrates, all standardized factor loadings exceeded the threshold of 0.40 . The composite reliability of all Model- 2 factors was greater than 0.60 , which indicated good reliability.

[Table 3]

As shown in Table 4, all correlations between factors were below 0.85, which suggested that the HPB-Bloat's discriminant validity was satisfactory.

[Table 4]

\section{Discussion}

The development of the HPB-Bloat and the evaluation of its validity and reliability are vital steps in assessing health-promoting behaviours among Malay-speaking patients who suffer from AB symptoms. The newly developed HPB-Bloat, based on the concept of TPB, has been proven to meet the validity and reliability standards through a multi-phase approach. The final version of the 17-item HPB-Bloat with four factors is ready to be used in future studies to evaluate health-promoting behaviours across the Malaysian population experiencing $\mathrm{AB}$ symptoms.

There are a few scales that measure health-promoting behaviours, for instance, the Health Promoting Lifestyle Profile (HPLP) (Duffy et al., 1996; Paudel et al., 2017; Walker et al., 1987), the HPLP-II (Malakouti et al., 2015; Mirghafourvand et al., 2015; Wei et al., 2012), the Adolescent Health Promotion Scale (AHPS) (Ortabag et al., 2011), and the Wellbeing and Health Promotion survey (El Ansari et al., 2011; El Ansari \& Stock, 2010). The HPLP and HPLP-II were developed to prevent diseases and lessen morbidity, while subsequently improving quality of life and cutting healthcare costs (Kuan et al., 2019; Lim et al., 2016; Mirghafourvand et al., 2015). The HPB-Bloat was introduced for these same reasons, but specifically for people with $\mathrm{AB}$.

Few studies have explored the connection between health-promoting behaviour and other causal factors such as social support, physical activity, gender, family size, obesity, and wellbeing (Baheiraei et al., 2011; Hubbard et al., 1984; Mirghafourvand et al., 2015; Wainwright et al., 2000). Sousa et al. (2015) suggested that a person's lifestyle factors accounted for $60 \%$ of their quality of health and life. The HPLP-II questionnaire is a scale that is commonly used to measure a person's overall health-promoting behaviours and lifestyle. However, AB patients often use different self-management strategies, which encouraged us to develop a new healthpromoting behaviour scale specifically for $\mathrm{AB}$.

In stressful or fast-paced environments, people often adopt unhealthy lifestyles and can develop chronic illnesses, including AB. Lifestyle management through health-promoting behaviour is a possible solution to this problem, and has been shown to improve disease and 
311 quality of life (Kuan et al., 2019; Musavian et al., 2014). The newly developed HPB-Bloat scale

312 may assist various health stakeholders, including physicians, psychologists, public health self-management. We recommend that future studies apply this new scale in different populations in order to analyze the stability of its performance.

There were strengths, but also limitations to the study. First, this study included individuals from the community (hospital compound) that had experienced $\mathrm{AB}$, rather than solely hospital-based patients. This was done so that the scale could be used to evaluate the general public rather than only patients. Second, we purposively sampled only from the northeastern region of Peninsular Malaysia, and therefore our results may not be generalizable to other populations. Additionally, the scale was designed to be applicable to the adult population and cannot be used to assess bloating or health-promoting behaviours in adolescents or children. Finally, the original scale was developed in the Malay language, so further validation studies with the scale translated into other languages, such as English, are needed.

\section{Conclusion}

In conclusion, we conducted several series of validation process to confirm that the newly developed HPB-Bloat scale and its four factors have good construct validity and structure. Future studies should apply the new HPB-Bloat across different populations, languages, and different health stakeholders in order to test its validity and stability over time.

\section{Acknowledgements}

We would like to thank all of the study's participants and supporting members.

\section{References}

Abdullah N, Kueh YC, Kuan G, Wong MS, Yahaya FH, Lee YY. 2020. Validity and reliability of the newly developed malay-language health belief of bloating (HB-Bloat) scale. International Journal of Environmental Research and Public Health, 17(8), 2773.

Ajzen I. 1991. The Theory of Planned Behavior. Organizational Behavior And Human Decision Processes. 50(2), 179-211.

Baheiraei A, Mirghafourvand M, Mohammadi E, Nedjat S, Charandabi SMA, Rajabi F, Majdzadeh R. 2011. Health-promoting behaviors and social support of women of reproductive age, and strategies for advancing their health: Protocol for a mixed methods study. BMC Public Health, 11(1), 191. https://doi.org/10.1186/1471-2458-11-191

Boyce P, Gilchrist, J, Talley NJ, Rose D. 2000. Cognitive-behaviour therapy as a treatment for irritable bowel syndrome: a pilot study. Australian and New Zealand Journal of Psychiatry, 34(2), 300-309. https://doi.org/10.1046/j.1440-1614.2000.00731.x

Cai Lian T, Bonn G, Si Han Y, Chin Choo Y, Chee Piau W. 2016. Physical activity and its correlates among adults in malaysia: a cross-sectional descriptive study. PLoS ONE, 11(6), e0157730. https://doi.org/10.1371/journal.pone.0157730

Cook CM, Schoeller DA. 2011. Physical activity and weight control: Conflicting findings. Current Opinion in Clinical Nutrition and Metabolic Care. 14(5), 419-424. https://doi.org/10.1097/MCO.0b013e328349b9ff

Delgado-Aros S, Locke GR, Camilleri M, Talley NJ, Fett S, Zinsmeister AR, Melton LJ. 2004. 
Obesity is associated with increased risk of gastrointestinal symptoms: A population-based study. American Journal of Gastroenterology, 99(9), 1801-1806. https://doi.org/10.1111/j.1572-0241.2004.30887.x

Drossman DA., Toner BB, Whitehead WE., Diamant NE, Dalton CB, Duncan S, Emmott S, Proffitt V, Akman D, Frusciante K, Le T, Meyer K, Bradshaw B, Mikul, K, Morris CB, Blackman CJ, Hu Y, Jia H, Li JZ, ... Bangdiwala SI. 2003. Cognitive-behavioral therapy versus education and desipramine versus placebo for moderate to severe functional bowel disorders. Gastroenterology, 125(1),19-31. https://doi.org/10.1016/S0016-5085(03)00669-3

Duffy ME., Rossow R, Hernandez M. 1996. Correlates of Health-Promotion Activities in Employed Mexican American Women. Nursing Research, 45(1), 18-24. https://doi.org/10.1097/00006199-199601000-00004

El Ansari W, Stock C. 2010. Is the health and wellbeing of university students associated with their academic performance? Cross sectional findings from the United Kingdom. International Journal of Environmental Research and Public Health, 7(2), 509-527. https://doi.org/10.3390/ijerph7020509

El Ansari, W, Stock C, Snelgrove S, Hu X, Parke S, Davies S, John J, Adetunji H, Stoate M, Deeny P, Phillips C, MabhalaA. 2011. Feeling healthy? A survey of physical and psychological wellbeing of students from seven universities in the UK. International Journal of Environmental Research and Public Health, 8(5), 1308-1323. https://doi.org/10.3390/ijerph8051308

Fernández-Bañares F, Rosinach M, Esteve M, Forné M, Espinós JC, Maria Viver J. 2006. Sugar malabsorption in functional abdominal bloating: A pilot study on the long-term effect of dietary treatment. Clinical Nutrition, 25(5), 824-831. https://doi.org/10.1016/j.clnu.2005.11.010

Foley A, Burgell R, Barret JS, Gibson, PR. 2014. Management Strategies for Abdominal Bloating and Distension. Gatroenterology and Hepatology, 10(9), 561-571. https://www.ncbi.nlm.nih.gov/pmc/articles/PMC4991532/

George D, Paul Mallery W. 2003. SPSS for Windows Step by Step A Simple Guide and Reference Fourth Edition (11.0 update) Answers to Selected Exercises. Allyn \& Bacon. https://wps.ablongman.com/wps/media/objects/385/394732/george4answers.pdf

Graff LA, Walker JR, Lix L, Clara I, Rawsthorne P, Rogala L, Miller N, Jakul L, McPhail, C, Ediger J, Bernstein CN. 2006. The Relationship of Inflammatory Bowel Disease Type and Activity to Psychological Functioning and Quality of Life. Clinical Gastroenterology and Hepatology, 4(12). https://doi.org/10.1016/j.cgh.2006.09.027

Hair JFJ, Black WC, Babin BJ, Anderson R.2010. Multivariate data analysis (7th ed.). Pearson Prentice Hall.

Han D, Iragorri N, Clement F, Lorenzetti D, Spackman E. 2018. Cost Effectiveness of Treatments for Chronic Constipation: A Systematic Review. Pharmacoeconomics, 36 (4), 435-449. Springer International Publishing. https://doi.org/10.1007/s40273-018-0609-6

Hinton P, Brownlow C, McMurray I. 2004. SPSS Explained. Taylor \& Francis.

Ho W, Spiegel BMR. 2008. The relationship between obesity and functional gastrointestinal disorders: Causation, association, or neither? Gastroenterology and Hepatology, 4(8), 572578. Millenium Medical Publishing.

Hox J.1997. From Theoretical Concept to Survey Question. In Survey Measurement and Process Quality, eds L. Lyberg, P.P. Biemer, M. Collins, E. de Leeuw, C. Dippo, N. Schwarz, and D.Trewin. New York: John Wiley and Sons. 
401

402

403

404

405

406

407

408

409

410

411

412

413

414

415

416

417

418

419

420

421

422

423

424

425

426

427

428

429

430

431

432

433

434

435

436

437

438

439

440

441

442

443

444

445

446

Hubbard P, Muhlenkamp AF, Brown N. 1984. The relationship between social support and selfcare practices. Nursing Research, 33(5), 266-270. https://doi.org/10.1097/00006199198409000-00004

Johannesson E. 2015. Intervention to increase physical activity in irritable bowel syndrome shows long-term positive effects. World Journal of Gastroenterology, 21(2), 600-608. https://doi.org/10.3748/wjg.v21.i2.600

Kaiser HF. 1974. An index of factorial simplicity. Psychometrika, 39(1), 31-36.

Karin S-E, Sabine L, Marcel S. 2019. Reliability of an Item Set Assessing Indoor Climate in Offices-Results From Field Studies and Laboratory Research. Frontiers in Built Environment, 5, 117. https://doi.org/10.3389/fbuil.2019.00117

Khoshoo V, Armstead C, Landry L. 2006. Effect of a laxative with and without tegaserod in adolescents with constipation predominant irritable bowel syndrome. Alimentary Pharmacology and Therapeutics, 23(1), 191-196. https://doi.org/10.1111/j.13652036.2006.02705.x

Kim HJ, Vazquez Roque MI, Camilleri, M, Stephens D, Burton DD, Baxter K, Thomforde G, Zinsmeister AR. 2005. A randomized controlled trial of a probiotic combination VSL\# 3 and placebo in irritable bowel syndrome with bloating. Neurogastroenterology and Motility, 17(5), 687-696. https://doi.org/10.1111/j.1365-2982.2005.00695.x

Kline RB. 2011. Principles And Practice Of Structural Equation Modeling. The Guilford Press.

Kua CH, Ng ST, Lhode R, Kowalski S, Gwee KA. 2012. Irritable bowel syndrome and other gastrointestinal disorders: Evaluating self-medication in an Asian community setting. International Journal of Clinical Pharmacy, 34(4), 561-568. https://doi.org/10.1007/s11096-012-9644-0

Kuan G, Kueh YC, Abdullah N, Tai ELM. 2019. Psychometric properties of the healthpromoting lifestyle profile II: Cross-cultural validation of the Malay language version. BMC Public Health, 19(1), 751. https://doi.org/10.1186/s12889-019-7109-2

Kueh YC, Morris T, Borkoles E, Shee H. 2015. Modelling of diabetes knowledge, attitudes, selfmanagement, and quality of life: A cross-sectional study with an Australian sample. Health and Quality of Life Outcomes, 13(1), 129. https://doi.org/10.1186/s12955-015-0303-8

Kueh YC, Morris T, Ismail AAS. 2017. The effect of diabetes knowledge and attitudes on selfmanagement and quality of life among people with type 2 diabetes. Psychology, Health and Medicine, 22(2), 138-144. https://doi.org/10.1080/13548506.2016.1147055

Lacy BE, Weiser K, Lee RDe. 2009. The treatment of irritable bowel syndrome. Therapeutic Advances in Gastroenterology, 2(4), 221-238. SAGE Publications. https://doi.org/10.1177/1756283X09104794

Lämås K, Lindholm L, Stenlund H, Engström B, Jacobsson C. 2009. Effects of abdominal massage in management of constipation-A randomized controlled trial. International Journal of Nursing Studies, 46(6), 759-767. https://doi.org/10.1016/j.ijnurstu.2009.01.007

Lim BC, Kueh YC, Arifin WN, Ng KH. 2016. Validation of health promoting lifestyle profile-II: A confirmatory study with a Malaysian undergraduate students sample. Education in Medicine Journal, 8(2), 65-77. https://doi.org/10.5959/eimj.v8i2.438

Liu JP, Yang M, Liu Y, We, ML, Grimsgaard S. 2006. Herbal medicines for treatment of irritable bowel syndrome. Cochrane Database of Systematic Reviews. https://doi.org/10.1002/14651858.cd004116.pub2

Lotfipur-Rafsanjani S, Ravari A, Ghorashi Z, Haji-Maghsoudi S, Akbarinasab J, Bekhradi R. 2018. Effects of geranium aromatherapy massage on premenstrual syndrome: A clinical

Peer] reviewing PDF | (2020:08:51849:2:0:NEW 17 Feb 2021) 
trial. International Journal of Preventive Medicine, 9(1), 98.

https://doi.org/10.4103/ijpvm.IJPVM_40_16

Lynn MR. 1986. Determination and quantification of content validity. Nursing Research, 35(6), 382-386. https://doi.org/10.1097/00006199-198611000-00017

Malakouti J, Sehhati F, Mirghafourvand M, Nahangi R. 2015. Relationship between Health Promoting Lifestyle and Perceived Stress in Pregnant Women with Preeclampsia. Journal of Caring Sciences, 4(2), 155-163. https://doi.org/10.15171/jcs.2015.016

McEachan RRC, Conner M. 2011. Prospective prediction of health-related behaviours with the Theory of Planned Behaviour: a meta-analysis. Journal Health Psychology Review, 2, $97-$ 144. https://doi.org/10.1080/17437199.2010.521684.

McFarland LV, Dublin S. 2008. Meta-analysis of probiotics for the treatment of irritable bowel syndrome. World Journal of Gastroenterology, 14(17), 2650-2661. Baishideng Publishing Group Inc. https://doi.org/10.3748/wjg.14.2650

Mirghafourvand M, Baheiraei A, Nedjat S, Mohammadi E, Charandabi SM-A, Majdzadeh R. 2015. A population-based study of health-promoting behaviors and their predictors in Iranian women of reproductive age. Health Promotion International, 30(3), 586-594. https://doi.org/10.1093/heapro/dat086

Moayyedi P, Ford AC, Talley NJ, Cremonini F, Foxx-Orenstein AE. Brandt LJ, Quigley EMM. 2010. The efficacy of probiotics in the treatment of irritable bowel syndrome: A systematic review. Gut, 59(3), 325-332. https://doi.org/10.1136/gut.2008.167270

Muthén LK, Muthén BO.(1998-2017. Mplus User's Guide. Eighth Edition. Los Angeles, CA: Muthén \& Muthén

Musavian AS, Pasha A, Rahebi S-M, Atrkar Roushan Z, Ghanbari A. 2014. Health promoting Behaviors Among Adolescents: A Cross-sectional Study. Nursing and Midwifery Studies, 3(1). https://doi.org/10.17795/nmsjournal14560

Mustapha WNW. 2018. Depression on the rise. New Straits Time. https://www.nst.com.my/opinion/columnists/2018/04/361026/depression-rise

Nicholl BI, Halder SL, Macfarlane GJ, Thompson DG, O’Brien S, Musleh M, McBeth J. 2008. Psychosocial risk markers for new onset irritable bowel syndrome - Results of a large prospective population-based study. Pain, 137(1), 147-155.

https://doi.org/10.1016/j.pain.2007.08.029

NST. 2018. Boy who ate instant noodles every day for years dies of stomach cancer. New Straits Time. https://www.nst.com.my/world/2018/10/422584/boy-who-ate-instant-noodles-everyday-years-dies-stomach-cancer

O'malley D, Quigley EMM, Dinan TG, Cryan JF. 2011. Do interactions between stress and immune responses lead to symptom exacerbations in irritable bowel syndrome? Brain, Behavior, and Immunity. 25 (7), 1333-1341. https//doi.org/10.1016/j.bbi.2011.04.009

Ortabag T, Ozdemir S, Bakir B, Tosun N. 2011. Health Promotion and Risk Behaviors Among Adolescents in Turkey. Journal of School Nursing, 27(4), 304-315. https://doi.org/10.1177/1059840511408322

Paudel S, GC KB, Bhandari DB, Bhandari L, Arjyal A. 2017. Health related lifestyle behaviors among undergraduate medical students in patan academy of health sciences in Nepal. Journal of Biosciences and Medicines, 5(9), 43-53. https://doi.org/10.4236/jbm.2017.59005

Patino CM, Ferreira JC. 2018. Inclusion and exclusion criteria in research studies: definitions and why they matter. J Bras Pneumol. 44(2):84. doi: 10.1590/s1806-37562018000000088. PMID: 29791550; PMCID: PMC6044655. 
493

494

495

496

497

498

499

500

501

502

503

504

505

506

507

508

509

510

511

512

513

514

515

516

517

518

519

520

521

522

523

524

525

526

527

528

529

530

531

532

533

534

535

536

537

538

Polit DF, Beck CT. 2006. The content validity index: Are you sure you know what's being reported? critique and recommendations. Research in Nursing \& Health, 29(5), 489-497. https://doi.org/10.1002/nur.20147

Prince SA, Adamo KB, Hamel ME, Hardt J, Connor Gorber S, Tremblay M. 2008. A comparison of direct versus self-report measures for assessing physical activity in adults: A systematic review. In International Journal of Behavioral Nutrition and Physical Activity 5,56. BioMed Central. https://doi.org/10.1186/1479-5868-5-56

Rashid FH. 2017. Malaysians most obese in region. New Straits Time. https://www.nst.com.my/news/nation/2017/06/246538/malaysians-most-obese-region

Sousa P, Gaspar P, Vaz DC, Gonzaga S, Dixe MA. 2015. Measuring health-promoting behaviors: Cross-cultural validation of the health-promoting lifestyle Profile-II. International Journal of Nursing Knowledge, 26(2), 54-61. https://doi.org/10.1111/20473095.12065

Sperber AD, Bangdiwala SI, Drossman DA, Ghoshal UC, Simren M, Tack J, Whitehead WE, Dumitrascu DL, Fang X, Fukudo S, Kellow J, Okeke E, Quigley EM, Schmulson M, Whorwell P, Archampong T, Adibi P, Andresen V, Benninga MA, ... Palsson OS. 2020. Worldwide Prevalence and Burden of Functional Gastrointestinal Disorders, Results of Rome Foundation Global Study. Gastroenterology. https://doi.org/10.1053/j.gastro.2020.04.014

Taber KS. 2018. The use of cronbach's alpha when developing and reporting research instruments in science education. Research in Science Education, 48(6), 1273-1296. https://doi.org/10.1007/s11165-016-9602-2

Thomson CE, White KM, Hamilton K. 2012. Investigating mothers' decisions about their child's sun-protective behaviour using the Theory of Planned Behaviour. Journal of Health Psychology, 17(7), 1001-1010. https://doi.org/10.1177/1359105311433905

Vejdani R, Shalmani HRM, Mir-Fattahi M, Sajed-Nia F, Abdollahi M, Zali MR, Alizadeh AHM, Bahari A, Amin G. 2006. The efficacy of an herbal medicine, Carmint, on the relief of abdominal pain and bloating in patients with irritable bowel syndrome: A pilot study. Digestive Diseases and Sciences, 51(8), 1501-1507. https://doi.org/10.1007/s10620-0069079-3

Viner R, Macfarlane A. 2005. Health promotion. BMJ, 330(7490), 527. https://doi.org/10.1136/bmj.330.7490.527

Vulevic J, Tzortzis G, Juric A, Gibson GR. 2018. Effect of a prebiotic galactooligosaccharide mixture (B-GOS $\left.{ }^{\circledR}\right)$ on gastrointestinal symptoms in adults selected from a general population who suffer with bloating, abdominal pain, or flatulence. Neurogastroenterology \& Motility, 30(11), e13440. https://doi.org/10.1111/nmo.13440

Wainwright P, Thomas J, Jones M. 2000. Health promotion and the role of the school nurse: A systematic review. In Journal of Advanced Nursing, 32(5), 1083-1091. https://doi.org/10.1046/j.1365-2648.2000.01579.x

Walker SN, Sechrist KR, Pender NJ. 1987. The health-promoting lifestyle profile: Development and psychometric characteristics. Nursing Research, 36(2), 76-81. https://doi.org/10.1097/00006199-198703000-00002

Wei CN, Harada K, Ueda K, Fukumoto, K., Minamoto K, Ueda A. 2012. Assessment of healthpromoting lifestyle profile in Japanese university students. Environmental Health and Preventive Medicine, 17(3), 222-227. https://doi.org/10.1007/s12199-011-0244-8

WHO. 2018. Physical activity. Available at https://www.who.int/news-room/fact-

Peer) reviewing PDF | (2020:08:51849:2:0:NEW 17 Feb 2021) 
539 sheets/detail/physical-activity (assessed 30th March 2020).

540 WHO. 2019. Malaysia and WHO call for more investment in primary health care the 21st

541 century. World Health Organization. Available at

542 https:/www.who.int/malaysia/news/detail/08-04-2019-malaysia-and-who-call-for-more-

543 investment-in-primary-health-care-the-21st-century (assesses $1^{\text {st }}$ March 2020).

544 Yong AG, Pearce S. 2013. A beginner's guide to factor analysis: Focusing on exploratory factor

$545 \quad$ analysis. Tutor Quant Methods Psychol, 9, 79-94.

$546 \quad$ https://doi.org/10.20982/tqmp.09.2.p079

547

548 
Figure 1

Figure 1: Summary of questionnaire development process 
Items generation:

1) Literature search for content related to HPB resulted in 24 items

2) In-depth interview resulted additional 1 item

3) Experts' input resulted additional 10 items and expected 5 domains

Total number of items $=35$

Temporary domains $=5$

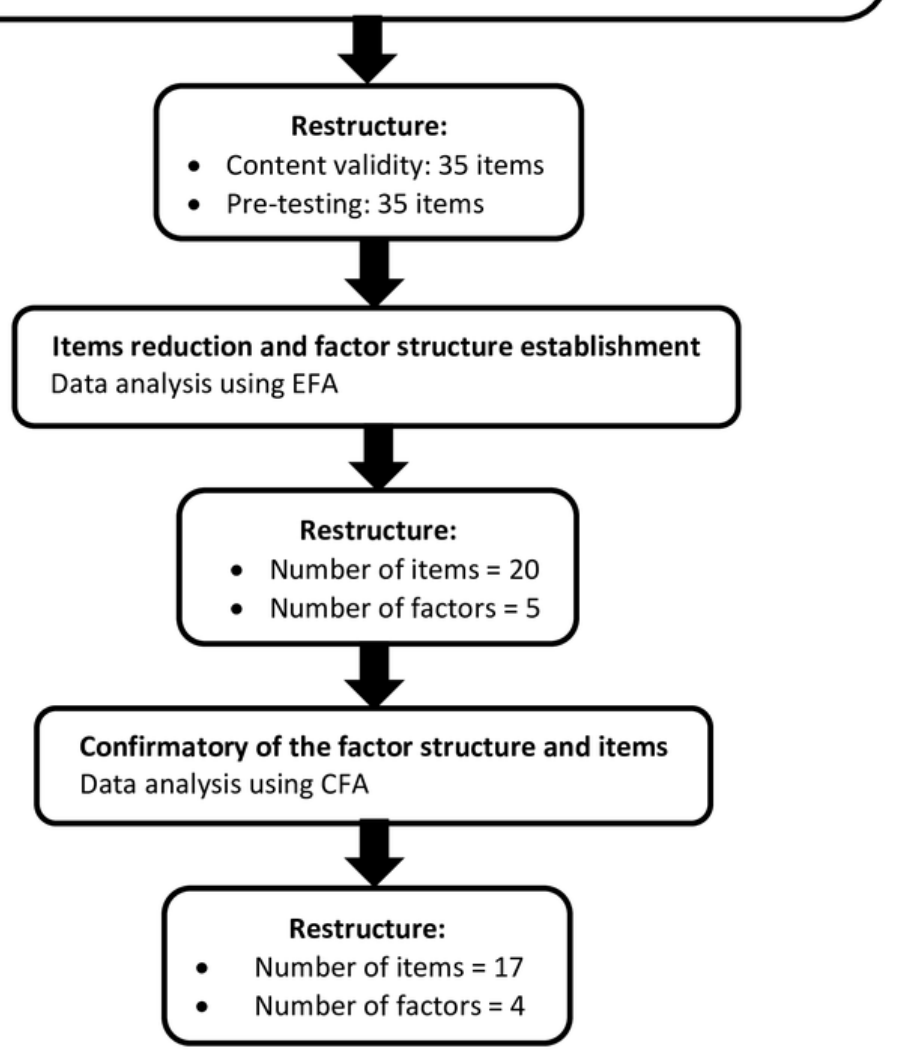

Figure 1: Summary of questionnaire development process. 


\section{Table $\mathbf{1}$ (on next page)}

Results of Descriptive Statistics, EFA, and Reliability

The 5 factors were described as diet, health awareness, physical activity, stress management, and treatment. 
1 Table 1. Results of Descriptive Statistics, EFA, and Reliability $(n=150)$

\begin{tabular}{|c|c|c|c|c|c|c|c|}
\hline \multirow{2}{*}{$\begin{array}{l}\text { No. abbreviated item } \\
\text { content }\end{array}$} & \multirow[t]{2}{*}{ Mean } & \multirow[t]{2}{*}{ SD } & \multicolumn{5}{|c|}{ Factor loading } \\
\hline & & & 1 & 2 & 3 & 4 & 5 \\
\hline D1 & 4.17 & 0.75 & 0.480 & & & & \\
\hline D2 & 4.07 & 0.85 & 0.370 & & & & \\
\hline D3 & 4.23 & 0.76 & 0.743 & & & & \\
\hline D4 & 3.98 & 0.91 & 0.599 & & & & \\
\hline D5 & 3.84 & 0.78 & - & & & & \\
\hline D6 & 4.33 & 0.53 & 0.697 & & & & \\
\hline D7 & 3.95 & 0.72 & - & & & & \\
\hline D8 & 3.37 & 0.95 & - & & & & \\
\hline D9 & 3.81 & 0.74 & - & & & & \\
\hline HA1 & 3.57 & 0.83 & & 0.484 & & & \\
\hline HA2 & 3.75 & 0.80 & & 0.755 & & & \\
\hline HA3 & 3.89 & 0.66 & & - & & & \\
\hline HA4 & 3.56 & 0.91 & & 0.671 & & & \\
\hline HA5 & 3.84 & 0.74 & & 0.902 & & & \\
\hline HA6 & 3.31 & 0.89 & & - & & & \\
\hline HA7 & 4.04 & 0.56 & & - & & & \\
\hline PA1 & 3.80 & 0.80 & & & - & & \\
\hline PA2 & 3.62 & 1.09 & & & 0.521 & & \\
\hline PA3 & 3.67 & 0.83 & & & 0.773 & & \\
\hline PA4 & 3.67 & 0.84 & & & 0.539 & & \\
\hline PA5 & 4.08 & 0.76 & & & - & & \\
\hline PA6 & 3.89 & 0.90 & & & - & & \\
\hline SM1 & 4.13 & 0.62 & & & & 0.287 & \\
\hline SM2 & 4.12 & 0.79 & & & & 0.495 & \\
\hline SM3 & 4.06 & 0.54 & & & & - & \\
\hline SM4 & 3.93 & 0.58 & & & & 0.561 & \\
\hline SM5 & 3.59 & 0.92 & & & & - & \\
\hline SM6 & 4.02 & 0.83 & & & & - & \\
\hline SM7 & 4.25 & 0.65 & & & & - & \\
\hline SM8 & 3.63 & 1.05 & & & & 0.543 & \\
\hline $\mathrm{T} 1$ & 3.48 & 1.17 & & & & & - \\
\hline $\mathrm{T} 2$ & 4.26 & 0.52 & & & & & 0.405 \\
\hline
\end{tabular}




\begin{tabular}{llllllll}
\hline T3 & 3.96 & 0.61 & & & & & 0.751 \\
T4 & 3.92 & 0.66 & & & & & 0.517 \\
T5 & 3.92 & 0.60 & & & & & 0.349 \\
Eigenvalue & & & 4.45 & 2.18 & 1.92 & 1.45 & 1.33 \\
Variance explained (\%) & & & 22.25 & 10.91 & 9.58 & 7.26 & 6.65 \\
Cumulative variance (\%) & & & 22.25 & 33.17 & 42.75 & 50.00 & 56.66 \\
Cronbach alpha & & & 0.74 & 0.81 & 0.64 & 0.52 & 0.58
\end{tabular}

2 Legend: $\mathrm{D}=$ Diet, HA: Health awareness, PA: Physical activity, SM=Stress management, $3 \mathrm{~T}=$ Treatment

4 


\section{Table 2 (on next page)}

Summary for HPB-Bloat model fit indices

The final model (Model 2) fit the data well based on several fit indices 
$1 \quad$ Table 2: Summary for HPB-Bloat model fit indices $(n=323)$.

\begin{tabular}{lllll}
\hline Path model & RMSEA $(90 \% \mathrm{CI})$ & CFI & TLI & SRMR
\end{tabular}

\begin{tabular}{llccc}
\hline Model-0 $^{\mathrm{a}}$ & $0.062(0.053,0.070)$ & 0.828 & 0.796 & 0.064 \\
Model-1 $^{\mathrm{b}}$ & $0.064(0.054,0.075)$ & 0.842 & 0.809 & 0.062 \\
Model-2 $^{\mathrm{c}}$ & $0.044(0.032,0.061)$ & 0.929 & 0.911 & 0.052 \\
\hline
\end{tabular}

a Model-0 with original model with 5 factors and 20 items.

bModel-1 with deleted problematic items; T2, T3, T5.

'Model-2 with additional correlated items residual; T4 with HA5, T4 with HA4, T4 with HA1, D6 with D2, SM4 with SM2. 


\section{Table 3(on next page)}

Standardized Factor Loading $(\lambda)$, and Composite Reliability of CFA Discriminant Validity Among Latent Variables of CFA in Model 2

All standardized factor loadings have exceeded the threshold of 0.40 .All correlations between factors were below 0.85 which suggest that discriminant validity of the HPB-Bloat was satisfied 
1 Table 3. Standardized Factor Loading $(\lambda)$, and Composite Reliability of CFA $(n=323)$.

\begin{tabular}{|c|c|c|c|c|c|c|}
\hline \multirow[t]{2}{*}{ Constructs/items } & \multirow[t]{2}{*}{ Mean } & \multirow[t]{2}{*}{ SD } & \multirow{2}{*}{$\frac{\text { Model-0 }}{\lambda}$} & \multirow{2}{*}{$\frac{\text { Model-1 }^{\#}}{\lambda}$} & \multicolumn{2}{|c|}{ Model-2 $2^{\#}$} \\
\hline & & & & & $\lambda$ & $\mathrm{CR}$ \\
\hline Diet & & & & & & 0.77 \\
\hline D1 & 4.04 & 0.74 & 0.57 & 0.60 & 0.59 & \\
\hline D2 & 3.91 & 0.92 & 0.51 & 0.56 & 0.61 & \\
\hline D3 & 4.14 & 0.86 & 0.65 & 0.61 & 0.60 & \\
\hline D4 & 3.95 & 0.91 & 0.68 & 0.72 & 0.70 & \\
\hline D6 & 4.20 & 0.68 & 0.66 & 0.60 & 0.65 & \\
\hline Health awareness & & & & & & 0.82 \\
\hline HA1 & 3.85 & 0.84 & 0.54 & 0.51 & 0.55 & \\
\hline HA2 & 4.11 & 0.70 & 0.65 & 0.62 & 0.63 & \\
\hline HA4 & 3.98 & 0.82 & 0.71 & 0.67 & 0.72 & \\
\hline HA5 & 3.99 & 0.76 & 0.79 & 0.83 & 0.77 & \\
\hline \multicolumn{7}{|l|}{ Treatment } \\
\hline $\mathrm{T} 2$ & 4.31 & 0.76 & 0.30 & - & - & \\
\hline T3 & 4.15 & 0.82 & 0.49 & - & - & \\
\hline $\mathrm{T} 4$ & 4.01 & 0.76 & 0.60 & $0.67 *$ & $0.67 *$ & \\
\hline $\mathrm{T} 5$ & 4.10 & 0.69 & 0.66 & - & - & \\
\hline Physical activity & & & & & & 0.64 \\
\hline PA2 & 4.13 & 0.83 & 0.48 & 0.48 & 0.46 & \\
\hline PA3 & 4.02 & 0.80 & 0.73 & 0.73 & 0.74 & \\
\hline PA4 & 4.03 & 0.78 & 0.62 & 0.62 & 0.62 & \\
\hline Stress management & & & & & & 0.69 \\
\hline SM1 & 4.40 & 0.60 & 0.45 & 0.46 & 0.43 & \\
\hline SM2 & 4.03 & 0.82 & 0.62 & 0.63 & 0.76 & \\
\hline SM4 & 3.97 & 0.83 & 0.60 & 0.59 & 0.73 & \\
\hline SM8 & 3.93 & 0.96 & 0.49 & 0.49 & 0.47 & \\
\hline
\end{tabular}


2 Note: $\lambda=$ standardized factor loading, $\mathrm{CR}=$ composite reliability, all factor loadings were 3 statistically significant at $\mathrm{p}<.050,{ }^{*} \mathrm{~T} 4$ was grouped into health awareness and the factor was 4 renamed as health and treatment awareness, "ffour-factor model consists of latent variables 5 diet, health and treatment awareness, physical activity, stress management. 


\section{Table 4 (on next page)}

Discriminant Validity Among Latent Variables of CFA in Model 2

All correlations between factors were below 0.85 which suggest that discriminant validity of the HPB-Bloat was satisfied 
1 Table 4. Discriminant Validity Among Latent Variables of CFA in Model $2(n=323)$.

Constructs/

$2 \quad 3 \quad 4$

Correlation coefficient, $r$

\begin{tabular}{lllll}
\hline 1. Diet & 1 & 0.83 & 0.68 & 0.51
\end{tabular}

2. Health and treatment awareness

$\begin{array}{lll}1 & 0.58 & 0.59\end{array}$

3. Physical activity

10.66

4. Stress management

1

2 Note: all correlation coefficients were statistically significant at $p<0.001$.

3

4 